\title{
Human sensitivity to temporal proximity: The role of spatial and temporal speed gradients
}

\author{
TOM C. A. FREEMAN \\ University of Aston, Birmingham, England \\ and \\ MIKE G. HARRIS and P. A. TYLER \\ University of Birmingham, Birmingham, England
}

\begin{abstract}
Estimates of temporal proximity (sometimes called time-to-collision) from random-dot flow patterns are shown to be based upon retinal speed, rather than upon changes in dot density. Neither the spatial nor the temporal gradient of motion is essential to the task, but estimates can be made from either alone. Performance is unaffected by the addition of rotational motion, suggesting that observers are capable of extracting the radial component of motion, which contains all the relevant information, from complex stimuli.
\end{abstract}

Movement of an observer through the world produces a smooth transformation of the retinal image containing information about the direction of movement and about the three-dimensional layout of surfaces in the world (Clocksin, 1980; Cutting, 1986; J. J. Gibson, Olum, \& Rosenblatt, 1955; Harris \& Freeman, 1990; Koenderink, 1985, 1986; Koenderink \& van Doorn, 1975, 1976; Lee, 1974; Longuet-Higgins \& Prazdny, 1980; Nakayama \& Loomis, 1974; Rieger \& Lawton, 1985; Waxman \& Wohn, 1988). Previous empirical work has established that human observers can make use of these transformations in a wide variety of tasks, including, for example, the recovery of locomotory heading (Warren \& Hannon, 1988; Warren, Morris, \& Kalish, 1988), three-dimensional surface layout (Harris, Freeman, \& Hughes, 1992; Landy, Dosher, Sperling, \& Perkins, 1991; Siegel \& Andersen, 1988; Treue, Husain, \& Andersen, 1991), surface rigidity (de Bruyn \& Orban, 1990), and relative depth (Braunstein, 1968; Braunstein \& Andersen, 1981; Flock, 1964; E. J. Gibson, J. J. Gibson, Smith, \& Flock, 1959; Rogers \& Graham, 1979, 1982, 1983, 1985).

In this paper, we concentrate upon the extraction of temporal proximity. (This variable is sometimes called timeto-contact, or time-to-collision, implying that its main use is in the control of locomotion. However, because it can be computed on a point-by-point basis and relates equally well to directions far from the locomotory heading, we

Some of this work was carried out while M.G.H. was on study leave in the Department of Vision Sciences, Aston University, and some of it was suppported by SERC Grant GR/H/52986. We thank Mark Georgeson and Steve Anderson for helpful suggestions and discussions. Address correspondence to M. G. Harris, Cognitive Science Research Centre, School of Psychology, The University of Birmingham, Birmingham, UK B15 2TT.

-Accepted by previous editor, Charles W. Eriksen prefer the term temporal proximity because it conveys the wider potential use in providing a time-based map of threedimensional surface layout.) Previous studies (Lee, 1976; Lee, Lishman, \& Thomson, 1982; Lee \& Reddish, 1981; Lee \& Thomson, 1982; Lee \& Young, 1985; Lee, Young, Reddish, Lough, \& Clayton, 1983; McLeod \& Ross, 1983; Schiff \& Detwiler, 1979; Todd, 1981; Tresilian, 1990) have shown that human observers and some animals can extract temporal proximity from suitable visual displays, but it is not clear from these studies which aspects of the stimulus they used.

Translation by the observer, in a straight line at a uniform speed and with a fixed angle of gaze, produces a uniform expansion of the image from a single focus of expansion (FoE) coinciding with the observer's locomotory heading (see, e.g., J. J. Gibson, 1950; Harris, Freeman, \& Williams, 1992). The speed of radial image motion increases linearly with distance from the FoE, so the transformation includes a smooth spatial speed gradient along each line of flow. Moreover, as an object gets closer, its image expands progressively faster so that, in addition to this spatial gradient, the image transformation includes a smooth temporal speed gradient. In an analysis of this and more complex situations, Lee (1976) has shown how temporal proximity, $\tau$, can be recovered from the instantaneous radial velocity of any point in the image, $r^{\prime}$, and its distance from the focus of expansion, $r$ :

$$
\tau=r / r^{\prime}
$$

In Appendix A, we reiterate this and also show how temporal proximity can be recovered from the radial acceleration, $r^{\prime \prime}$, at a fixed point in the image:

$$
\tau=2 r^{\prime} / r^{\prime \prime}
$$

Thus, temporal proximity can, in principle, be recovered from the image using either the spatial gradient (Equation 1) by measuring radial image speed at a known po- 
sition in the image, or the temporal gradient (Equation 2) by measuring the radial speed and acceleration at any fixed position. In this paper, we first confirm that human observers can make consistent estimates of temporal proximity from a simple visual display, and then we examine the role of spatial and temporal speed gradients as well as other possible cues in the performance of this task.

\section{EXPERIMENT 1}

In Experiment 1 we introduce a simple paradigm for estimating sensitivity to temporal proximity. Observers viewed a dynamic random-dot pattern depicting a flat, frontoparallel surface that approached them on a direct collision path. After a few moments the pattern disappeared, and the observers indicated, by pressing a button at the appropriate time, when they thought the surface would have reached them. This experiment was also an investigation of the role of stimulus velocity, display duration, and dot density in performing this task.

\section{Method}

Stimulus. The stimulus was generated by a DEC LSI 11/23+ computer and displayed via a standard laboratory interface (CED 502) upon an oscilloscope screen (Hewlett Packard 1304A, P31 phosphor) at a frame rate of $50 \mathrm{~Hz}$. It consisted of an annular pattern of dots, with a constant outer diameter of $10^{\circ}$ and a constant inner diameter of $2^{\circ}$. Each dot was of constant size and was randomly positioned within the annulus. Even in conditions involving small numbers of dots, no positional constraints were imposed upon the randomization. A small fixation point was provided at the center of the annulus. The dots moved radially, as though placed upon a frontoparallel surface that was moving directly toward the observer. In Experiments 1 and 2 , retinal dot speed ranged from $0.125^{\circ} / \mathrm{sec}$ to $5 \% \mathrm{sec}$, depending upon the condition, display time, and position of the dot. Dots reaching the outer perimeter of the annulus were extinguished and replaced at a random position on the inner perimeter with a probability equivalent to that of a real, randomly textured surface approaching from behind a fixed annular window.

The observer viewed the display monocularly from a distance of $57 \mathrm{~cm}$ through a viewing tube that excluded ambient light so that only the stimulus dots and the fixation point were visible. The nonviewing eye was covered by a translucent lens that prevented pattern vision, but preserved reasonable light adaptation.

Procedure. In each trial a random combination of temporal proximity, dot density, stimulus duration, and virtual surface velocity was presented. To keep these factors orthogonal while presenting a sufficient range of each for the subsequent regression analysis, the randomization procedure was constrained as follows. Each factor was divided into a low and a high range, as detailed in Table 1. For each factor on each trial, a random value was chosen from one of the ranges and, in blocks of 16 trials, all combinations of high and low ranges for each of the four factors were selected in random order. This procedure did not preserve complete orthogonality, but throughout Experiments 1 and 2 the correlation between factors was typically very close to zero and never exceeded |.15|. To discourage the observer from treating the estimate of temporal proximity as a simple dichotomy between low and high ranges, dummy trials were randomly inserted between the experimental trials, with a probability of 0.1 . The stimulus parameters on these dummy trials were randomly chosen from the full range available (e.g., 1-5 sec for temporal proximity) and the responses, though collected, were not recorded.

Each trial began with the presentation of a screen containing only the central fixation point. Following a "ready" tone from the com-
Table 1

Randomization Ranges for Experiment 1

\begin{tabular}{llcc}
\hline \multicolumn{1}{c}{ Factor } & \multicolumn{1}{c}{ Units } & Low Range & High Range \\
\hline$\tau$ & seconds & $1.0-2.0$ & $4.0-5.0$ \\
Duration & seconds & $0.5-1.2$ & $2.3-3.0$ \\
Dot density & no. of dots & $4-68$ & $192-256$ \\
Velocity & centimeters/second & $60-160$ & $360-460$ \\
\hline
\end{tabular}

puter, the observer fixated this point and pressed a button to start the trial. After a delay of $0.5 \mathrm{sec}$, the stimulus was presented for the appropriate duration. The observer pressed the same button to indicate the time at which he/she thought the stimulus would have reached him/her, had it continued on its previous path. Feedback was given in the form of two tones, the frequency ratio of which indicated the ratio of the actual to the estimated temporal proximity.

Each session consisted of three blocks of 16 experimental trials. Two of the authors, both well-corrected myopes and experienced psychophysical observers, each undertook eight sessions, for a total of 384 experimental trials.

\section{Results}

The results of the 2 observers are very similar and, for both of them, there is a clear relationship between the actual and estimated temporal proximity of the stimulus. The results of a separate multiple regression on each observer's data are summarized in Table 2 . As would be expected, because this parameter was not directly available from the stimulus, the virtual velocity of the surface had no significant effect upon judgments. However, for both of the observers, dot density had a small but consistent effect: larger numbers of dots tended to be associated with shorter judgments of temporal proximity. In addition, the effect of stimulus duration hovered around significance, although the direction of this effect was different for the 2 observers. Most important for the purposes of this paper is that although the task was obviously difficult, the judgments of both of the observers were primarily determined by temporal proximity [for M.G.H., $R^{2}=.495, F(4,379)$ $=94.89, p<.001$; temporal proximity term accounts for $94.7 \%$ of the sequential SS regression. For T.C.A.F., $R^{2}=.479, F(4,379)=89.18, p<.001$; temporal proximity term accounts for $88.8 \%$ of the SS regression].

As a check that the observers were not simply performing the task as a simple dichotomy into short and long temporal proximities, the data for these two ranges were

Table 2

Summary of Overall Multiple Regression for Experiment 1

\begin{tabular}{lcrl}
\hline \multicolumn{1}{c}{ Term } & Coefficient & $t$ ratio & $p$ \\
\hline & Observer M.G.H. & & \\
Intercept & +1.6980 & 12.68 & $<.001$ \\
Velocity & -0.0002 & 0.94 & $>.05$ \\
Duration & -0.0761 & 2.00 & $=.046$ \\
Dot density & -0.0014 & 3.57 & $<.001$ \\
Temporal proximity & +0.4529 & 18.96 & $<.001$ \\
& Observer T.C.A.F. & & \\
Intercept & +1.2212 & 7.84 & $<.001$ \\
Velocity & -0.0002 & 0.56 & $>.05$ \\
Duration & +0.0832 & 1.88 & $=.061$ \\
Dot density & -0.0027 & 6.14 & $<.001$ \\
Temporal proximity & +0.5002 & 17.77 & $<.001$ \\
\hline
\end{tabular}


separately analyzed and the results are summarized in Tables 3 and 4 . Both of the observers continued to show a consistent ability to estimate temporal proximity within the short-range conditions, indicating that they were not treating the task as a simple dichotomy [for M.G.H., $R^{2}=.154, F(4,187)=9.71, p<.01$; temporal proximity term accounts for $53.7 \%$ of the SS regression. For T.C.A.F., $R^{2}=.428, F(4,187)=36.01, p<.001$; temporal proximity term accounts for $24.2 \%$ of the SS regression]. However, neither observer performed the task reliably within the long temporal proximity range [for M.G.H., $R^{2}=.038, F(4,187)=2.89, p<.05$; temporal proximity term accounts for $1.4 \%$ of the SS regression. For T.C.A.F., $R^{2}=.005, F(4,187)=1.22, p>$ .05 ; temporal proximity term accounts for $23.5 \%$ of the SS regression].

Despite the clear relationship, both of the observers tended to overestimate short temporal proximities and underestimate long temporal proximities. For Observer M.G.H., the mean estimated temporal proximity in the short range was $2.013 \mathrm{sec}$ against an actual mean of $1.517 \mathrm{sec}$, with a mean difference between estimated and actual proximities of $0.496 \mathrm{sec}$ and a standard deviation of $0.686 \mathrm{sec}$. The equivalent figures for Observer T.C.A.F. were a mean estimate of $1.817 \mathrm{sec}$ against an actual mean of $1.517 \mathrm{sec}$, with a mean difference of $0.299 \mathrm{sec}$ and a standard deviation of $0.781 \mathrm{sec}$. At the longer range of temporal proximities, the mean estimate for Observer M.G.H. was $3.388 \mathrm{sec}$ against an actual mean of $4.535 \mathrm{sec}$, with a mean difference between estimates and actual values of $1.147 \mathrm{sec}$ and a standard deviation of $0.816 \mathrm{sec}$. The equivalent figures for T.C.A.F. were a mean estimate of $3.292 \mathrm{sec}$ against an actual mean of $4.500 \mathrm{sec}$, with a mean difference of $1.208 \mathrm{sec}$ and a standard deviation of $0.977 \mathrm{sec}$. Of course some of the variability in these data can be accounted for by the variation in other relevant factors, such as dot density and display duration.

\section{Discussion}

The results confirm that both of the observers were capable of extracting information about temporal prox-

Table 3

Summary of Multiple Regression for Short

Temporal Proximities in Experiment 1

\begin{tabular}{lccc}
\hline \multicolumn{1}{c}{ Term } & Coefficient & $t$ ratio & $p$ \\
\hline & Observer M.G.H. & & \\
Intercept & +1.0563 & 3.45 & $<.001$ \\
Velocity & +0.0001 & 0.34 & $>.05$ \\
Duration & +0.0195 & 0.39 & $>.05$ \\
Dot density & -0.0018 & 3.58 & $<.001$ \\
Temporal proximity & +0.7440 & 4.57 & $<.001$ \\
& Observer T.C.A.F. & & \\
Intercept & +0.4153 & 1.40 & $<.05$ \\
Velocity & +0.0010 & 3.10 & $>.01$ \\
Duration & +0.1363 & 2.93 & $<.01$ \\
Dot density & -0.0043 & 9.20 & $<.001$ \\
Temporal proximity & +0.9773 & 5.90 & $<.001$ \\
\hline
\end{tabular}

Table 4

Summary of Multiple Regression for Long

Temporal Proximities in Experiment 1

\begin{tabular}{lccc}
\hline \multicolumn{1}{c}{ Term } & Coefficient & $t$ ratio & $p$ \\
\cline { 2 - 4 } & Observer M.G.H. & & \\
Intercept & +3.5717 & 4.35 & $<.001$ \\
Velocity & -0.0005 & 1.40 & $>.05$ \\
Duration & -0.1576 & 2.78 & $<.01$ \\
Dot density & -0.0008 & 1.49 & $>.05$ \\
Temporal proximity & +0.0727 & 0.41 & $>.05$ \\
& Observer T.C.A.F. & & \\
Intercept & +2.4070 & 2.25 & $<.05$ \\
Velocity & -0.0005 & 0.98 & $>.05$ \\
Duration & +0.0228 & 0.32 & $>.05$ \\
Dot density & -0.0011 & 1.64 & $>.05$ \\
Temporal proximity & +0.2495 & 1.08 & $>.05$ \\
\hline
\end{tabular}

imity from our simple visual displays, but they suggest a tendency to overestimate at short intervals and underestimate at long intervals. These findings are broadly compatible with the generally reported tendency to underestimate temporal proximity, in that the slope of the function relating estimated to actual proximity was, for both observers, considerably less than 1 ; it is the addition of a significant intercept that produces the overestimation at short intervals. It is sometimes suggested (McLeod \& Ross, 1983) that underestimation constitutes a safe and ecologically sensible strategy. However, the tendency found here to overestimate at short intervals is clearly not ecologically sensible, and, although underestimation might appear safe, the most generally sensible strategy would surely be to make veridical estimates. The inaccuracies in our own results are, in fact, almost certainly artifactual, at least in part. There is some suggestion that both of the observers treated the task partly as a simple dichotomy, because the regression for the overall data is much better than the regressions on the individual subranges. At short temporal proximities the coefficient associated with true temporal proximity is closer to 1 , but at long temporal proximities there is no reliable relationship at all. The inaccuracies might also be due to difficulties in estimating temporal periods rather than to difficulties in extracting the necessary information from the display, and this would provide an alternative account of the superiority of the overall regression over those for the individual subranges. In any event, although the simple task of indicating temporal proximity by a timed buttonpress may not provide an accurate absolute estimate, it should not overestimate human ability, and, provided the reasons for inaccuracies remain consistent, it should provide an adequate basis for comparison of performance under different conditions.

\section{EXPERIMENT 2}

The results from Experiment 1 confirmed that human observers can extract information about temporal proximity from simple visual displays. In Experiment 2 we 
investigated which aspects of the stimulus are important in this task by selectively manipulating the spatial and temporal speed gradients that normally characterize an approaching stimulus.

\section{Method}

Stimuli. In Experiment 2 we used the "normal" stimulus described above and introduced three further conditions. In the no spatial gradient condition, the instantaneous speed of all the dots was the same, irrespective of their distance from the FoE. On each frame, all the dots were assigned the average speed from the corresponding frame of the normal condition. This produced a display compatible with a virtual surface's deforming so that its central region approached the observer faster than its edges, and, indeed, this is how it appeared. In the no temporal gradient condition, spatial gradients were preserved but dot speeds remained constant over time. On all frames, the spatial speed gradient was multiplied by a constant temporal factor, calculated as the average over frames in the normal condition. This produced a display compatible with a rigid surface's decelerating as it approached the observer, and, again, this is how it was perceived. Finally, in the no spatial or temporal gradient condition, both spatial and temporal gradients were replaced by the average constant speeds described above, producing a display compatible with (and appearing as) a deforming and decelerating surface.

Procedure. The procedure was similar to that described in Experiment 1 . Each session was an investigation of one of the four stimulus conditions described above. The same 2 observers each undertook two sessions (a total of 96 trials) for each of the four conditions, in a different random order.

\section{Results}

Stimuli in which the speed gradients have been manipulated do not have an unambiguous temporal proximity,

Table 5

Summary of Multiple Regressions for Experiment 2, Observer M.G.H.

\begin{tabular}{|c|c|c|c|}
\hline Term & Coefficient & $t$ ratio & $\underline{p}$ \\
\hline \multicolumn{4}{|c|}{ Both Gradients Present } \\
\hline $\begin{array}{l}\text { Intercept } \\
\text { Velocity } \\
\text { Duration } \\
\text { Dot density } \\
\text { Temporal proximity }\end{array}$ & $\begin{array}{l}+0.6987 \\
-0.0003 \\
+0.2433 \\
-0.0015 \\
+0.6820\end{array}$ & $\begin{array}{r}2.09 \\
0.54 \\
2.65 \\
1.65 \\
11.84\end{array}$ & $\begin{array}{l}<.05 \\
>.05 \\
<.01 \\
>.05 \\
<.001\end{array}$ \\
\hline \multicolumn{4}{|c|}{ No Spatial Gradients } \\
\hline $\begin{array}{l}\text { Intercept } \\
\text { Velocity } \\
\text { Duration } \\
\text { Dot density } \\
\text { Temporal proximity }\end{array}$ & $\begin{array}{c}+1.1556 \\
+0.0005 \\
+0.0399 \\
0 \\
+0.4132\end{array}$ & $\begin{array}{l}4.68 \\
1.15 \\
0.56 \\
0.07 \\
9.50\end{array}$ & $\begin{array}{l}<.001 \\
>.05 \\
>.05 \\
>.05 \\
<.001\end{array}$ \\
\hline \multicolumn{4}{|c|}{ No Temporal Gradients } \\
\hline $\begin{array}{l}\text { Intercept } \\
\text { Velocity } \\
\text { Duration } \\
\text { Dot density } \\
\text { Temporal proximity }\end{array}$ & $\begin{array}{l}+0.8337 \\
+0.0001 \\
+0.3517 \\
-0.0014 \\
+0.4741\end{array}$ & $\begin{array}{r}2.96 \\
0.13 \\
4.71 \\
1.79 \\
10.08\end{array}$ & $\begin{array}{l}<.01 \\
>.05 \\
<.001 \\
>.05 \\
<.001\end{array}$ \\
\hline \multicolumn{4}{|c|}{ No Spatial or Temporal Gradients } \\
\hline $\begin{array}{l}\text { Intercept } \\
\text { Velocity } \\
\text { Duration } \\
\text { Dot density } \\
\text { Temporal proximity }\end{array}$ & $\begin{array}{c}+1.5126 \\
0 \\
+0.1501 \\
+0.0011 \\
+0.4026 \\
\end{array}$ & $\begin{array}{l}5.91 \\
0.02 \\
2.00 \\
1.43 \\
8.58 \\
\end{array}$ & $\begin{array}{l}<.001 \\
>.05 \\
=.049 \\
>.05 \\
<.001\end{array}$ \\
\hline
\end{tabular}

Table 6

Summary of Multiple Regressions for Experiment 2, Observer T.C.A.F.

\begin{tabular}{|c|c|c|c|}
\hline Term & Coefficient & $t$ ratio & $p$ \\
\hline \multicolumn{4}{|c|}{ Both Gradients Present } \\
\hline $\begin{array}{l}\text { Intercept } \\
\text { Velocity } \\
\text { Duration } \\
\text { Dot density } \\
\text { Temporal proximity }\end{array}$ & $\begin{array}{l}+1.3751 \\
-0.0009 \\
+0.1641 \\
-0.0040 \\
+0.7734\end{array}$ & $\begin{array}{r}4.92 \\
1.68 \\
2.06 \\
5.20 \\
15.80\end{array}$ & $\begin{array}{l}<.001 \\
>.05 \\
=.042 \\
<.001 \\
<.001\end{array}$ \\
\hline \multicolumn{4}{|c|}{ No Spatial Gradients } \\
\hline $\begin{array}{l}\text { Intercept } \\
\text { Velocity } \\
\text { Duration } \\
\text { Dot density } \\
\text { Temporal proximity }\end{array}$ & $\begin{array}{l}+1.5991 \\
+0.0004 \\
+0.1663 \\
-0.0029 \\
+0.5130\end{array}$ & $\begin{array}{l}5.46 \\
0.73 \\
2.00 \\
3.56 \\
9.64\end{array}$ & $\begin{array}{l}<.001 \\
>.05 \\
=.049 \\
=.001 \\
<.001\end{array}$ \\
\hline \multicolumn{4}{|c|}{ No Temporal Gradients } \\
\hline $\begin{array}{l}\text { Intercept } \\
\text { Velocity } \\
\text { Duration } \\
\text { Dot density } \\
\text { Temporal proximity }\end{array}$ & $\begin{array}{l}+1.5872 \\
-0.0007 \\
+0.1906 \\
-0.0017 \\
+0.5103\end{array}$ & $\begin{array}{r}6.49 \\
1.51 \\
2.72 \\
2.42 \\
12.26\end{array}$ & $\begin{array}{l}<.01 \\
>.05 \\
<.01 \\
<.05 \\
<.001\end{array}$ \\
\hline \multicolumn{4}{|c|}{ No Spatial or Temporal Gradients } \\
\hline $\begin{array}{l}\text { Intercept } \\
\text { Velocity } \\
\text { Duration } \\
\text { Dot density } \\
\text { Temporal proximity }\end{array}$ & $\begin{array}{l}+1.9389 \\
-0.0011 \\
+0.1588 \\
-0.0007 \\
+0.4617\end{array}$ & $\begin{array}{l}6.50 \\
2.02 \\
1.85 \\
0.80 \\
8.18\end{array}$ & $\begin{array}{l}<.001 \\
=.047 \\
=.067 \\
>.05 \\
<.001\end{array}$ \\
\hline
\end{tabular}

and so present the observer with a complex task. For example, in the absence of a spatial gradient, temporal proximity varies systematically with distance from the FoE, but in the absence of a temporal gradient, it changes nonlinearly over time. In the regression analysis described below, predicted temporal proximity was calculated by averaging over space and/or time, as appropriate. If the observers did not adopt a similar strategy, the regression will tend to underestimate performance. Specifically, if the observers used a different criterion, the magnitude of the regression coefficients will not be accurate, but, provided the criterion was linearly related to that used in the analysis, measures of variability, such as $R^{2}$, will be unaffected. Thus, assuming that the observers adopted similar strategies under different stimulus conditions, broad comparisons of performance between conditions are possible. Moreover, even without such comparisons, evidence that some ability remains when only part of the normal information is available is, of course, informative.

The basic multiple regression results are summarized separately for each observer in Tables 5 and 6 . A further summary of these analyses is provided in Table 7. The effects of virtual velocity, display duration, and dot density were, for all four stimulus conditions, broadly similar to those found in Experiment 1, and it is clear from Table 7 that judgments were primarily influenced by the information about temporal proximity that was carried by the stimulus. Most important, even though performance did deteriorate when speed gradients were systematically removed from the stimulus, consistent judgments could still be made. It does not appear that either spatial or tem- 
Table 7

Overall Summary of Regressions for Experiment 2

\begin{tabular}{lccc}
\multicolumn{1}{c}{ Stimulus Condition } & $R^{2}$ & $F(4,91)$ & $\begin{array}{c}\text { Percent SS } \\
\text { Regression }\end{array}$ \\
\hline & Observer M.G.H. & \\
Normal & 60.0 & 36.58 & 95.9 \\
No spatial gradient & 47.9 & 22.86 & 98.9 \\
No temporal gradient & 57.0 & 32.54 & 78.1 \\
No gradients & 45.2 & 20.62 & 89.2 \\
& Observer T.C.A.F. & \\
Normal & 74.9 & 71.89 & 86.9 \\
No spatial gradient & 53.2 & 28.03 & 82.9 \\
No temporal gradient & 62.4 & 40.39 & 93.1 \\
No gradients & 42.7 & 18.7 & 89.4 \\
\hline
\end{tabular}

Note-All $F$ ratios significant at $p<.001$. The rightmost column shows the percentage of the SS regression accounted for by the temporal proximity term.

poral gradients are more important for the task and, most surprisingly, some information about temporal proximity can still be extracted when both of these sources of information are removed. A summary of the means and standard deviations for the 2 observers in the short and long ranges of temporal proximity is given in Table 8 .

\section{Discussion}

The finding that our observers were able to make some use of temporal gradients in estimating temporal proximity stands in contrast to that of Todd (1981). Todd found that his observers made negligible use of dot accelerations (i.e., temporal gradients) in estimating landing position from displays depicting ballistic trajectories, and adopted more complex, learned strategies requiring estimates of simpler display parameters instead. It remains to be seen whether temporal gradients can only be estimated under some stimulus conditions or whether they are only used in certain tasks.

What information about temporal proximity did the subjects use in the no spatial or temporal gradient condition? The two most obvious candidates are changes in overall dot density and the average speed of the dots in the display. When an observer approaches a textured surface, the expansion of its image is accompanied by a progressive decrease in the texture density of the image. This change in texture density contains information about temporal proximity (Appendix B), and this cue was present in our stimuli because only the appropriate proportion of dots reaching the outer edge of the display window was replaced at its inner edge.

Generally, an observer cannot simply make use of the average speed of flow, but must also take into account the spatial distribution of speeds (e.g., Equation 1). However, our simple displays always depicted the same segment of the flow pattern, so that this spatial distribution was largely redundant. The observers could, in effect, make comparative judgments of temporal proximity simply by comparing the average speeds of the displays. In Experiment 3 we investigated the role of these two possible cues by further refining the stimuli.

\section{EXPERIMENT 3}

In Experiment 3 we investigated the role of speed gradients by systematically removing them from the display, as in Experiment 2. In addition, we manipulated the additional cues to temporal proximity provided by changes in dot density and average speed. To simplify the experiment, we did not systematically manipulate virtual velocity, display duration, or absolute dot density.

\section{Method}

Stimuli. The stimuli were those used in Experiment 2, with two additional refinements. First, in order to remove the potential cue of changes in dot density, the display contained a constant number of dots. Each dot had a finite lifetime of $100 \mathrm{msec}$, and the dots were randomly repositioned when their lifetime expired or if they reached the outer edge of the display window. It is conceivable that the observers could monitor the equivalent of instantaneous dot density changes by counting the number of dots extinguished at the edge of the display, but this seems unlikely given the generally "twinkling" nature of the stimulus. Second, in order to make the use of average speeds more difficult, each dot was assigned a rota-

Table 8

Means and Standard Deviations for Experiment 2

\begin{tabular}{|c|c|c|c|c|c|c|c|c|c|c|c|c|}
\hline & \multicolumn{6}{|c|}{ Low Range } & \multicolumn{6}{|c|}{ High Range } \\
\hline & \multicolumn{2}{|c|}{ Real TP } & \multicolumn{2}{|c|}{ Est TP } & \multicolumn{2}{|c|}{ |Real-Est $\mid$} & \multicolumn{2}{|c|}{ Real TP } & \multicolumn{2}{|c|}{ Est TP } & \multicolumn{2}{|c|}{ |Real-Est| } \\
\hline & $M$ & $S D$ & $M$ & $S D$ & $M$ & $S D$ & $M$ & $S D$ & $M$ & $S D$ & $M$ & $S D$ \\
\hline \multicolumn{13}{|c|}{ Observer M.G.H. } \\
\hline $\begin{array}{l}\text { Both } \\
\text { NS } \\
\text { NT } \\
\text { NST }\end{array}$ & $\begin{array}{l}1,526 \\
1,520 \\
1,487 \\
1,477\end{array}$ & $\begin{array}{l}267 \\
284 \\
291 \\
307\end{array}$ & $\begin{array}{l}1,919 \\
2,005 \\
2,004 \\
2,528\end{array}$ & $\begin{array}{l}855 \\
679 \\
767 \\
682\end{array}$ & $\begin{array}{r}392 \\
484 \\
517 \\
1,051\end{array}$ & $\begin{array}{l}820 \\
636 \\
744 \\
635\end{array}$ & $\begin{array}{l}4,502 \\
4,536 \\
4,507 \\
4,520\end{array}$ & $\begin{array}{l}269 \\
276 \\
281 \\
304\end{array}$ & $\begin{array}{l}3,935 \\
3,229 \\
3,397 \\
3,763\end{array}$ & $\begin{array}{l}910 \\
655 \\
854 \\
789\end{array}$ & $\begin{array}{r}567 \\
1,307 \\
1,111 \\
757\end{array}$ & $\begin{array}{l}945 \\
676 \\
817 \\
835\end{array}$ \\
\hline \multicolumn{13}{|c|}{ Observer T.C.A.F. } \\
\hline $\begin{array}{l}\text { Both } \\
\text { NS } \\
\text { NT } \\
\text { NST } \\
\end{array}$ & $\begin{array}{l}1,514 \\
1,574 \\
1,494 \\
1,534\end{array}$ & $\begin{array}{l}241 \\
286 \\
323 \\
266\end{array}$ & $\begin{array}{l}2,098 \\
2,454 \\
2,278 \\
2,515\end{array}$ & $\begin{array}{l}932 \\
961 \\
771 \\
891 \\
\end{array}$ & $\begin{array}{l}584 \\
880 \\
785 \\
981\end{array}$ & $\begin{array}{l}848 \\
918 \\
792 \\
864 \\
\end{array}$ & $\begin{array}{l}4,547 \\
4,519 \\
4,549 \\
4,477 \\
\end{array}$ & $\begin{array}{l}281 \\
280 \\
296 \\
288 \\
\end{array}$ & $\begin{array}{l}4,432 \\
3,948 \\
3,830 \\
3,879\end{array}$ & $\begin{array}{l}838 \\
761 \\
570 \\
799 \\
\end{array}$ & $\begin{array}{l}115 \\
571 \\
719 \\
598\end{array}$ & $\begin{array}{l}847 \\
747 \\
606 \\
856\end{array}$ \\
\hline
\end{tabular}

Note-TP = temporal proximity; Est = estimated; Both = both spatial and temporal gradients present; NS = no spatial gradient present; NT $=$ no temporal gradient present; NST $=$ no spatial or temporal gradient present. All data are in milliseconds. 
Table 9

Summary of Stimulus Conditions Used in Experiment 4

\begin{tabular}{cccccc}
$\begin{array}{c}\text { Stimulus } \\
\text { Condition }\end{array}$ & $\begin{array}{c}\text { Temporal } \\
\text { Proximity }\end{array}$ & $\begin{array}{c}\text { Duration } \\
\text { (seconds) }\end{array}$ & $\begin{array}{c}\text { Start Position } \\
(z \text { units })\end{array}$ & $\begin{array}{c}\text { End Position } \\
(z \text { units })\end{array}$ & $\begin{array}{c}\text { Speed } \\
(z \text { units/sec) }\end{array}$ \\
\hline 1 & 2 & 2 & 20 & 10 & 5 \\
2 & 1 & 1 & 20 & 10 & 10 \\
3 & 2 & 1 & 30 & 20 & 10 \\
4 & 1 & 0.5 & 30 & 20 & 20 \\
\hline
\end{tabular}

tional (i.e., tangential) as well as an expanding (i.e., radial) component of motion. This rotational component was computed so that the overall dot speed remained constant over both space and time. Thus, for example, in stimuli containing spatial radial speed gradients, the tangential component was greater near the center of the display than at the edges. Similarly, for stimuli containing temporal radial speed gradients, the tangential component was greater at the beginning of the display than at the end. In this situation, the observer may still make comparative judgments of temporal proximity using average speed, but must base the comparison only on the radial component, rather than on the overall speed, of each dot motion. Because the amplitudes of both radial and tangential components change over space and time, the decomposition into radial and tangential components cannot be avoided simply by attending to the change in overall dot speed (as would be possible if the amplitude of the tangential component were constant).

Procedure. The observers' task and the main experimental procedures were those used in Experiments 1 and 2. However, in this simplified experiment, all the displays depicted the same virtual velocity ( $256.5 \mathrm{~cm} / \mathrm{sec}$ ), contained the same number of dots $(180)$, and had the same duration $(1,760 \mathrm{msec})$. In sessions involving only radial motion, retinal dot speed varied from $0.174^{\circ} / \mathrm{sec}$ to $10 \% / \mathrm{sec}$, depending upon condition, display time, and dot position. In sessions with added rotating motion, retinal dot speed was constant throughout at $10.5 \% \mathrm{sec}$. Each session consisted of 48 trials and was an investigation of one of four speed gradient conditions (normal, no spatial, no temporal, or neither) and two rotation (no rotation or added rotation) conditions. On each trial, temporal proximity was randomly selected from the full range $0.5-4 \mathrm{sec}$. Observer M.G.H. undertook 16 sessions, 2 at each of the eight stimulus conditions ( 4 gradients $\times 2$ rotations), and Observer T.C.A.F. undertook 8 sessions, 1 at each of the stimulus conditions, in different random orders.

\section{Results}

Typical results are shown as scatterplots in Figure 1. These raw data were analyzed by simple linear regression, and the results are summarized separately for the 2 observers in Figures 2 and 3. The left-hand panels of these figures show the results for simple expanding stimuli, and the right-hand panels show those for stimuli with added rotation. The upper panels show the regression slopes, indicating the accuracy of the judgments, and the lower panels show the $R^{2}$ values, indicating the variability of judgments. In all cases, the regression was significant at the $1 \%$ level at least.

\section{Discussion}

The overall pattern of results is clear. First, the observers made reasonable judgments of temporal proximity, even when changes in overall dot density were removed from the display. In fact, for Observer M.G.H., Figure 4 shows a replication of the Experiment 3 proce- dure combined with the dot replacement strategy of Experiments 1 and 2. A comparison of Figures 2 and 4 suggests that dot density changes did not consistently help this observer.

Second, the observers made reasonable judgments of temporal proximity in the absence of overall density changes, even when speed gradients were also removed from the stimulus and even when overall dot speeds remained constant both within and between trials. If the observers made use of average speed cues under these conditions, then they must first have decomposed the overall flow pattern into its separate expanding and rotating components.

\section{EXPERIMENT 4}

In Experiment 4 we generalized some of our findings to a wider range of observers by using a simplified display and procedure. Observers estimated temporal proximity in the presence of rotational masks at a range of amplitudes.

\section{Method}

Stimuli. The stimuli were generated as in the previous experiments, except that the frame rate was $67 \mathrm{~Hz}$ and the display consisted of 90 dots randomly distributed within a circular window that subtended a diameter of $10^{\circ}$. A bright fixation point was provided at the center of this pattern. As before, the dots were of constant size and moved radially as though upon a frontoparallel surface that directly approached the observer. Dots moving outside the display window were permanently deleted. Radial retinal speeds varied from $0 \% \mathrm{sec}$ to $5 \% \mathrm{sec}$, depending upon condition, display time, and dot position. In addition to the radial motion, each dot could also be assigned a tangential motion with, in different conditions, an amplitude of $0^{\circ}, 1.38^{\circ}, 2.75^{\circ}, 4.13^{\circ}$, or $5.51^{\circ} / \mathrm{sec}$. The observers viewed the display monocularly from a distance of $57 \mathrm{~cm}$, using the arrangement described above.

Procedure. Only two temporal proximity values were used, but other stimulus factors were varied, as shown in Table 9. A brief glance at this table shows, for example, that any influence of stimulus distance should show up as a difference in performance in Conditions 2 and 3.

At the beginning of each trial the stationary stimulus appeared for $300 \mathrm{msec}$, accompanied by a low-pitched tone. At the end of this interval, the tone ceased and the stimulus moved for the appropriate duration and then disappeared. The observer indicated the time that the surface would have reached him/her by pressing a button. No feedback was given. The observer then indicated whether the display had appeared "near" or "far" by a second buttonpress. Again, no feedback was given.

Each session involved 120 randomly ordered experimental trials, consisting of three replications of 5 rotation amplitudes $\times 2$ rotation directions $\times$ the 4 stimulus conditions described in Table 9 . 


\section{a) NO ROTATION}

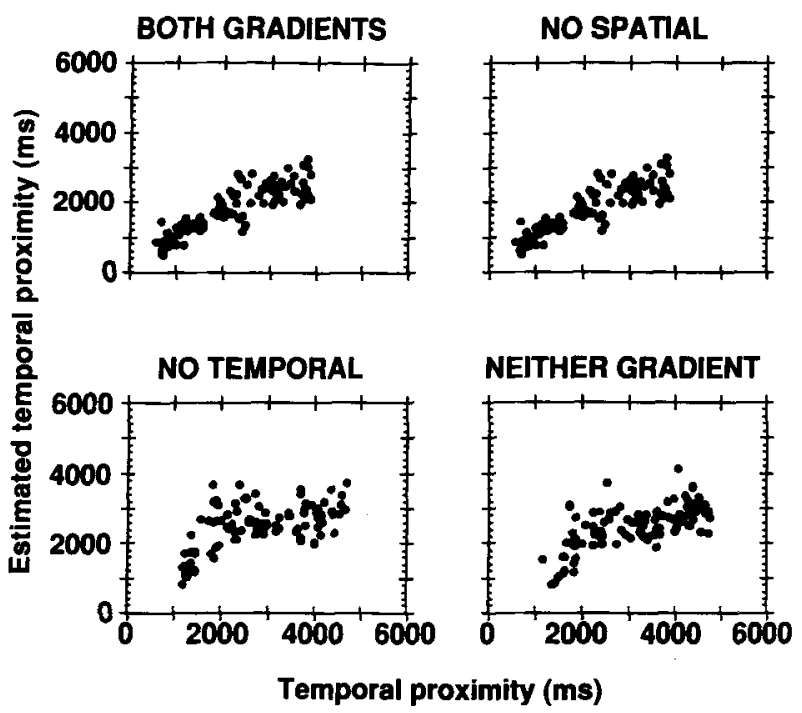

b) ADDED ROTATION

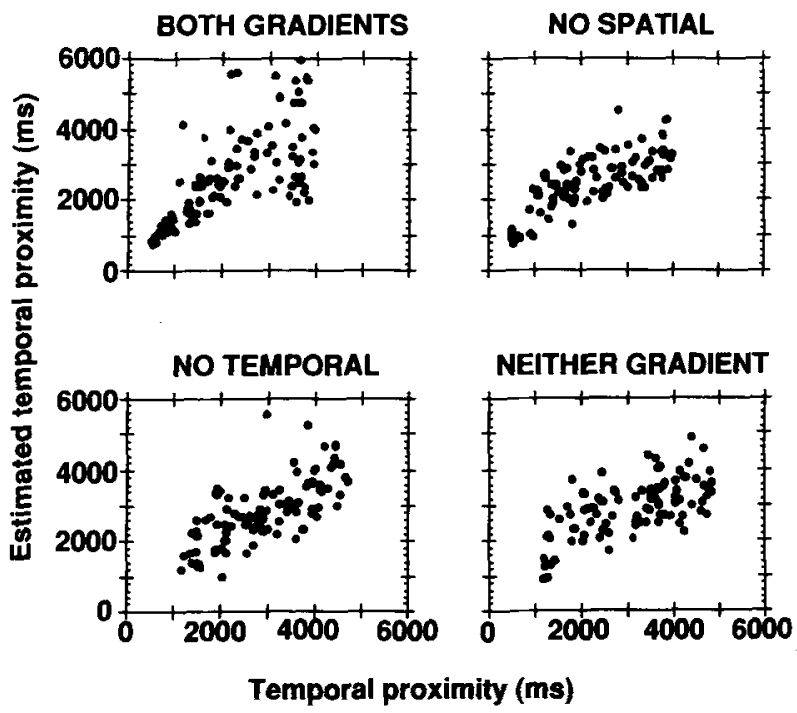

Figure 1. Scatterplots of the data from Observer M.G.H. in Experiment 3. Shown are no rotation (a) and added rotation (b). See text for details of stimuli.

A 16-trial practice period was included at the start of each session, comprising 1 trial of each of the 4 stimulus conditions combined with clockwise or anticlockwise rotation at $0^{\circ}$ or $5.51 \% \mathrm{sec}$.

Six paid observers with normal or corrected-to-normal vision each undertook a single session. All were naive to the aims of the study and either worked in or were students at the School of Psychology, The University of Birmingham.

\section{Results}

Figure 5 shows the temporal proximity estimates for the four stimulus conditions, averaged across observers and rotation directions, and plotted as a function of rota- tional amplitude. It appears that the observers were capable of making reliable estimates of temporal proximity. even in the presence of rotating masks, and that their performance was largely unaffected by such factors as stimulus duration. This interpretation was supported by a three-factor repeated measures ANOVA (mask amplitude $\times$ surface distance $\times$ temporal proximity), which revealed a significant main effect of temporal proximity $[F(1,5)=22.84, p<.005]$, but no other significant main effect or interaction. It was further supported by pooling the data across rotational amplitudes and performing a separate $t$ test for each of the four stimulus conditions. None of these tests revealed a significant difference between estimated and actual temporal proximity [Condition $1, M=1.87 \mathrm{sec}, t(5)=-0.56, p>.5$; Condition $2, M=1.31 \mathrm{sec}, t(5)=2.45, p>.05$; Condition 3, $M=1.75 \mathrm{sec}, t(5)=-1.65, p>.1$; Condition $4, M=$ $1.19 \mathrm{sec}, t(5)=1.46, p>.2$. All tests were two-tailed].

Figure 5 also shows the percentage of "near" responses, averaged across observers and rotational amplitudes in the four stimulus conditions. Performance did not differ significantly from chance $\left[\chi^{2}(3)=6.6, p>.05\right]$, providing further reassurance that the observers did not attempt to interpret some aspect of the display as an indicator of distance and then infer temporal proximity indirectly.

\section{Discussion}

As in Experiment 3, the observers were able reliably to estimate temporal proximity, and this ability was largely
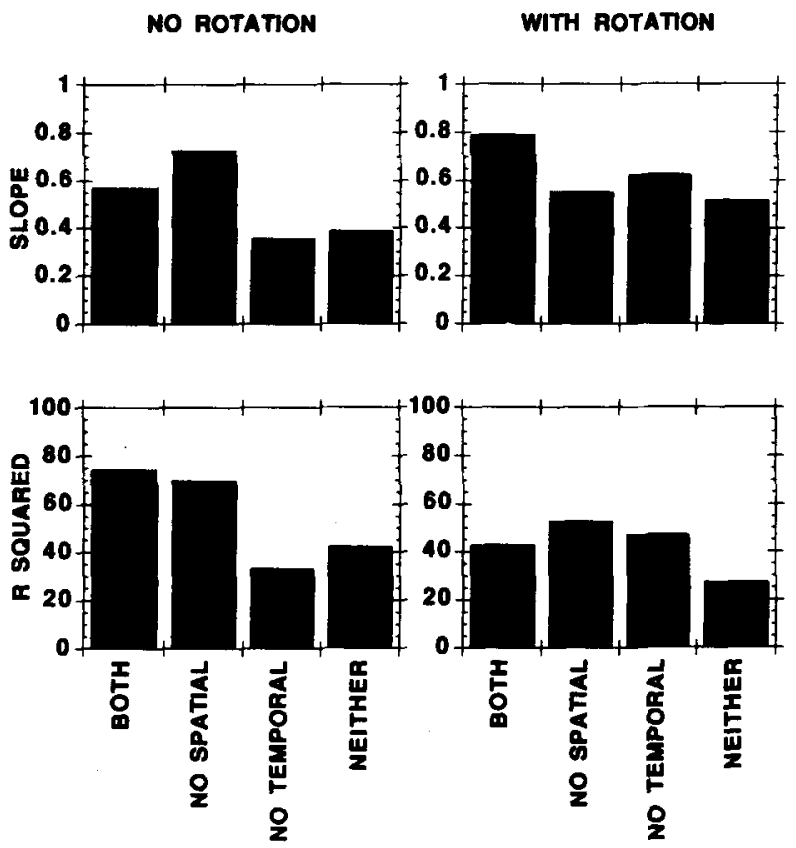

Figure 2. Summary of results from Experiment 3: The influence of spatial and temporal speed gradients on judgments of temporal proximity (Subject M.G.H.). Left panels, expanding stimuli; right panels, expanding and rotating stimuli. Top panels, stopes of regression of perceived temporal proximity on actual temporal proximity; bottom panels, coeficicients of determinance $\left(R^{2}\right)$ for the same regressions. 
unaffected by the addition of rotational masking motion. It remains possible that, in this experiment, the observers based their estimates upon changes in dot density rather than upon the radial speeds in the display. However, to account for the data, any strategy based upon dot density would have to be fairly sophisticated. The overall reduction in dot density from the start to the end of the display was $75 \%$ in Conditions 1 and 2, and $56 \%$ in Conditions 3 and 4 , yet estimates of temporal proximity were similar across these pairs of conditions, and near/far responses suggest that the observers were not able to use this potential cue, at least in estimating distance. Dividing the overall change in density by display duration would produce different values for all four conditions, which again is at odds with the similarity in performance. If the observers used dot density, they presumably based their estimates upon instantaneous changes, along the lines described in Appendix B. Even this strategy, of course, could not account for performance in Experiment 3, in which the dot density of the display was kept constant.

\section{GENERAL DISCUSSION}

Observers' estimates of temporal proximity do seem to be based upon the radial motion of looming displays. Although neither spatial nor temporal gradients are essential to the task, both seem to help because performance

NO ROTATION
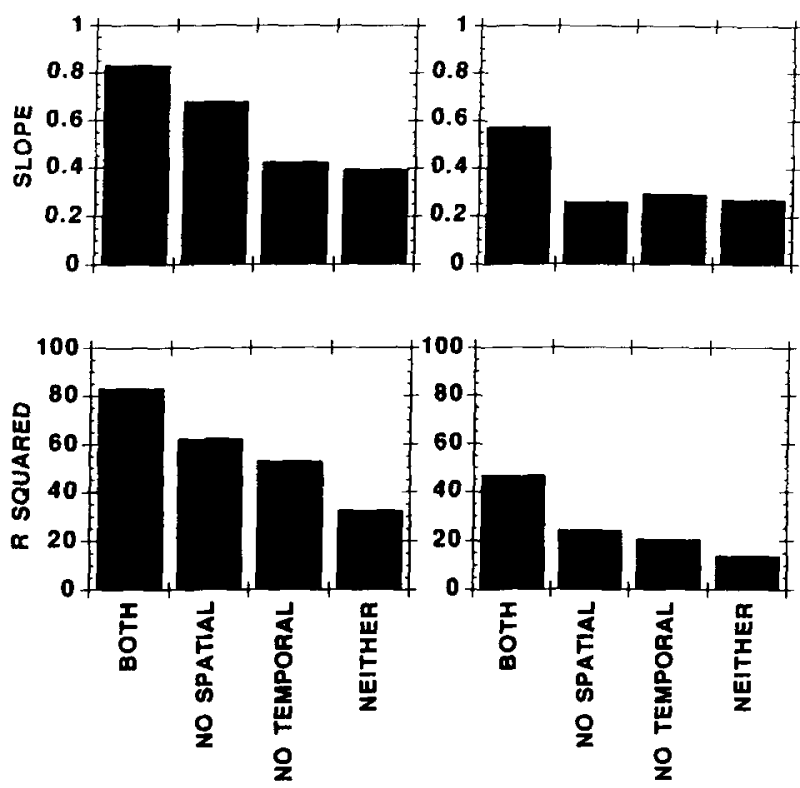

Figure 3. Summary of results from Experiment 3: The influence of spatial and temporal speed gradients on judgments of temporal proximity (Subject T.C.A.F.). Left panels, expanding stimuli; right panels, expanding and rotating stimuli. Top panels, slopes of regression of perceived temporal proximity on actual temporal proximity; bottom panels, coefificients of determinance $\left(R^{2}\right)$ for the same regressions.
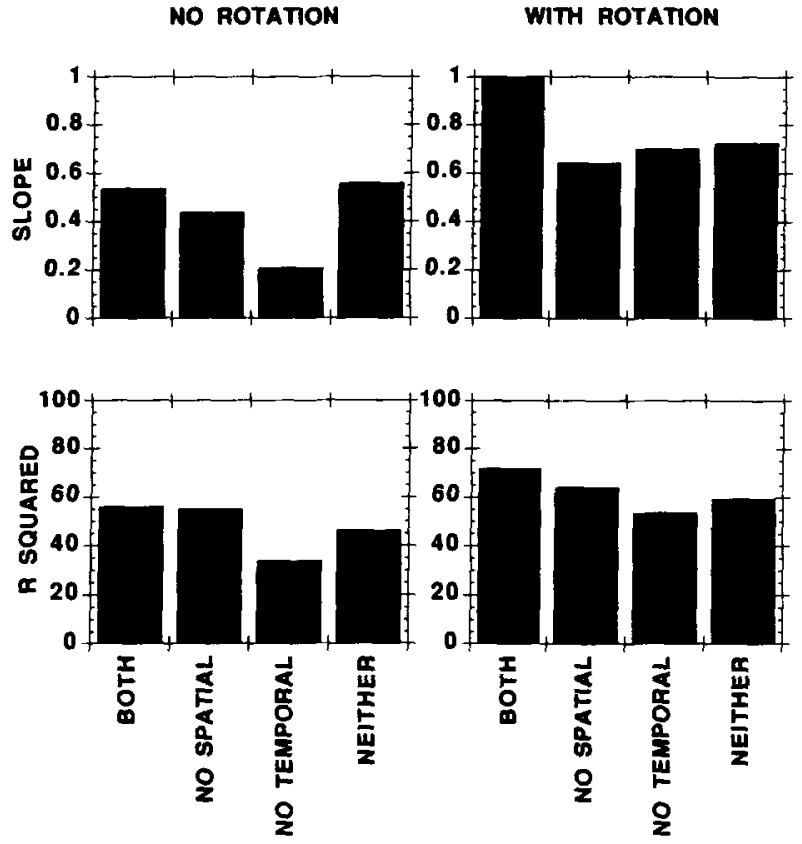

Figure 4. Summary of results from Experiment 3: The influence of spatial and temporal speed gradients on judgments of temporal proximity (Subject M.G.H.); stimuli containing no dot density changes. Left panels, expanding stimuli; right panels, expanding and rotating stimuli. Top panels, slopes of regression of perceived temporal proximity on actual temporal proximity; bottom panels, coefincients of determinance $\left(R^{2}\right)$ for the same regressions.

declines when either of these cues is removed. In the absence of both gradients, performance seems to be based upon average radial speed, rather than changes in dot density, because removal of density cues produces no further deterioration in performance. In making their estimates, observers seem capable of extracting the radial component of motion from complex displays, because performance is not affected by the addition of rotational motion.

We have previously shown (Freeman \& Harris, 1992) that complex displays can be decomposed into expanding and rotating directional components at threshold, and this ability fits well both with previous psychophysical work (Beverley \& Regan, 1979a, 1979b; Cavanagh \& Favreau, 1980; Marmolin, 1977; Regan \& Beverley, 1978a, 1978b, $1979,1982,1985)$ and with neurophysiological studies of single cells in the monkey cortex that are selectively sensitive to rotating or expanding motion (Regan \& Cynader, 1979; Saito et al., 1986; J. I. Simpson, Graf, \& Leonard, 1981; Tanaka, Fukada, \& Saito, 1989; Tanaka \& Saito, 1989). Although these mechanisms are not themselves sensitive to speed, they may function to recover the true position of "landmarks" such as the FoE, which are given by the overall directional structure of the flow. The work reported here suggests one role for this decomposition in a meaningful, suprathreshold task: In order to estimate temporal proximity from retinal flow, the observer must measure only the radial component of 
the overall motion at each retinal point, and one way to do this is by first recovering the true position of the FoE. In the displays used here, of course, the decomposition is fairly simple because the FoE is always present and its position is unaffected by the rotations we chose. Neither of these simplifications is always possible in natural flow patterns, and it would be interesting to know whether temporal proximity can be estimated from more complex displays. It is also interesting that W. A. Simpson (1988) found that the ability to discriminate temporal proximity was adversely affected by the addition of rotating motion. The discrepancy between these results and our own may be due to differences in the task (estimation vs. discrimination), to differences in the amplitude of the rotating masks, or to differences in the type of stimulus used. W. A. Simpson used rectilinear crosses rather than random-dot patterns, and, depending upon the width of the lines making up the cross, rotation of these stimuli may also introduce a substantial expanding motion.

Although observers seem to use radial speed rather than other potential cues to temporal proximity, such as changes in dot density, they do seem to be fairly flexible in their strategy, being able to use either spatial or temporal speed
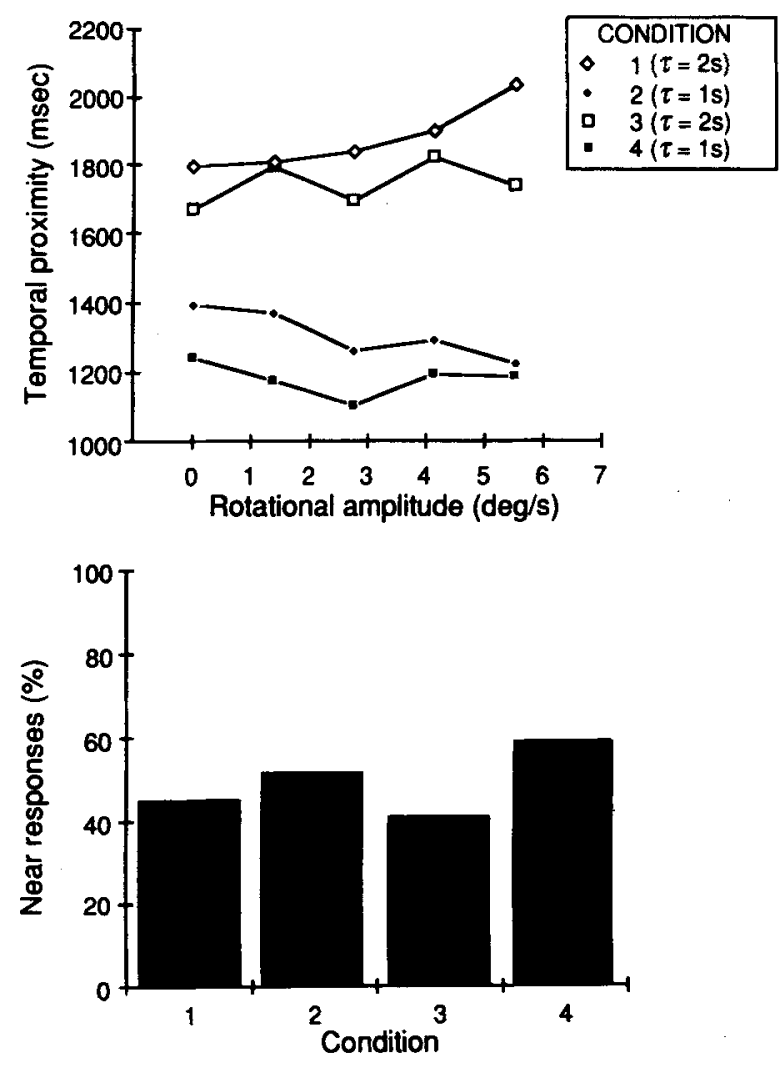

Figure 5. Summary of results from Experiment 4. Data from 6 observers and two rotational directions. Top panel: estimates of temporal proximity as a function of rotational amplitude for the four stimulus conditions described in Table 9. Bottom panel: percentage of "near" responses for the same four conditions. gradients. Of course some deterioration in performance is to be expected when either of these gradients is removed from the stimulus, because this presents the observer with a complex, ambiguous, and somewhat unnatural task. The more interesting point is that some performance does persist under these conditions, demonstrating the ability to make use of the remaining cues. In the words of Dr. Johnson (Boswell, 1763/1934), "It is not done well; but you are surprised to find it done at all" (p. 463).

It is perhaps most surprising that, in the absence of any speed gradients, observers resort to using average radial speed. This strategy would be of little general use in the natural world, unless confined only to temporal averaging. Spatial averaging works for the restricted set of conditions used in these experiments only because the displays consistently represented the same segment of the flow pattern, so that radial distances could largely be ignored. In the natural world, radial speed must generally be scaled by radial distance if it is to provide a reliable estimate of temporal proximity. Further experiments, in which observers are presented with different segments of the flow pattern, would reveal whether this potentially dangerous strategy is general, or whether it simply reflects the flexibility of the visual system in dealing with specific experimental tasks.

\section{REFERENCES}

Beverley, K. I., Regan, D. (1979a). Separable aftereffects of changing-size and motion-in-depth: Different neural mechanisms? $\mathrm{Vi}$ sion Research, 19, 727-732.

BeverLey, K. I., \& ReGAN, D. (1979b). Visual perception of changing size: The effect of object size. Vision Research, 19, 1093-1104.

Boswell, J. (1934). Life of Samuel Johnson. (L. F. Powell, Ed.). Oxford: Oxford University Press, Clarendon Press. (Original work published 1763)

Braunstein, M. L. (1968). Motion and texture as sources of slant information. Journal of Experimental Psychology, 78, 247-253.

Braunstein, M. L., \& Andersen, G. J. (1981). Velocity gradients and relative depth perception. Perception \& Psychophysics, 29, 145-155.

Cavanagh, P., \& Favreau, O. E. (1980). Motion aftereffect: A global mechanism for the perception of rotation. Perception, 9, 175-182.

Clocksin, W. H. (1980). Perception of surface slant and edge labels for optical flow: A computational approach. Perception, 9, 253-269.

Curting, J. E. (1986). Perception with an eye for motion. Cambridge, MA: MIT Press.

de Bruyn, B., \& Orban, G. A. (1990). The importance of velocity gradients in the perception of three-dimensional rigidity. Perception, 19, 21-27.

FLOCK, H. R. (1964). Some conditions sufficient for accurate monocular perceptions of moving surface slants. Joumal of Experimental Psychology, 67, 560-572.

Freeman, T. C. A., \& Harris, M. G. (1992). Human sensitivity to expanding and rotating motion: Effects of complementary masking and directional structure. Vision Research, 32, 81-87.

Gibson, E. J., Gibson, J. J., Smith, O. W., \& Flock, H. (1959). Motion parallax as a determinant of perceived depth. Journal of Experimental Psychology, 58, 40-51.

GIBson, J. J. (1950). The perception of the visual world. Boston: Houghton Mifflin.

Gibson, J. J., Olum, P., \& Rosenblatt, F. (1955). Parallax and perspective during aircraft landings. American Journal of Psychology, 68, 372-385. 
Harris, M. G., \& Freeman, T. C. A. (1990). The analysis and possible usage of retinal flow. In D. Travis (Ed.), Applying visual psycho physics to user interface design (pp. 95-108). Martlesham Heath, U.K.: British Telecom.

Harris, M. G, Freeman, T. C. A., \& Hughes, J. R. (1992). Retinal speed gradients and the perception of surface slant. Vision Research, 32, 587-590.

Harris, M. G., Freeman, T. C. A., \& Williams, G. H. (1992). Surface layout from retinal flow. In G. W. Humphreys (Ed.), Understanding vision: An interdisciplinary perspective (pp. 199-231). Oxford: Blackwell.

KoENDERINK, J. J. (1985). Space, form, and optical deformations. In D. T. Ingle, M. Jeannerod, \& D. N. Lee (Eds.), Brain mechanisms and spatial vision (pp. 32-58). Dordrecht: Martinus Nijhoff.

KoENDERJNK, J. J. (1986). Optic flow. Vision Research, 26, 161-180.

Koenderink, J. J., \& VAN DoORN, A. J. (1975). Invariant properties of the motion parallax field due to the movement of rigid bodies relative to the observer. Optica Acta, 22, 773-791.

KoEnderink, J. J., \& VAN DOORN, A. J. (1976). Local structure of movement parallax of the plane. Journal of the Optical Society of America, 66, 717-723.

Landy, M. S., Dosher, B. A., Sperling, G., \& Perkins, M. E. (1991). The kinetic depth effect and optic flow: II. First- and second-order motion. Vision Research, 31, 859-876.

LEE, D. N. (1974). Visual information during locomotion. In R. B. MacLeod \& H. L. Pick (Eds.), Perception: Essays in honor of $J$. J. Gibson (pp. 250-267). Ithaca, NY: Cornell University Press.

LEE, D. N. (1976). A theory of visual control of braking based on information about time-to-collision. Perception, 5, 437-459.

LeE, D. N., Lishman, J. R., \& Thomson, J. A. (1982). Regulations of gait in long jumping. Journal of Experimental Psychology: Human Perception \& Performance, 8, 448-459.

LEE, D. N., REDDISH, P. E. (1981). Plummeting gannets: A paradigm of ecological optics. Nature, 293, 293-294.

LEE, D. N., \& THOMSON, J. A. (1982). Vision in action: The control of locomotion. In D. T. Ingle, M. Goodale, \& R. Mansfield (Eds.), Analysis of visual behavior (pp. 411-433). Cambridge, MA: MIT Press.

LEE, D. N., \& Young, D. S. (1985). Visual timing of interceptive action. In D. T. Ingle, M. Jeannerod, \& D. N. Lee (Eds.), Brain mechanisms and spatial vision (pp. 1-31). Dordrecht: Martinus Nijhoff.

Lee, D. N., Young, D. S., Reddish, P. E., Lough, S., \& Clayton, T. M. H. (1983). Visual timing in hitting an accelerating ball. Quarterly Journal of Experimental Psychology, 35A, 333-346.

Longuet-Higgins, H. C., \& Prazdny, K. (1980). The interpretation of a moving retinal image. Proceedings of the Royal Society of London: Series $B, 208,385-397$.

MARMolIN, H. (1977). Three- and two-dimensional motion after-effects: Evidence for motion vector sensitive units. Scandinavian Journal of Psychology, 18, 192-202.

MCLeOD, R. W., \& Ross, H. E. (1983). Optic-flow and cognitive factors in time-to-collision estimates. Perception, 12, 417-423.

NaKayama, K., Loomis, L. M. (1974). Optical velocity patterns, velocity sensitive neurons, and space perception: A hypothesis. Perception, 3, 63-80.

REGAN, D., \& BEVERLEY, K. I. (1978a). Illusory motion in depth: Aftereffect of adaptation to changing size. Vision Research, 18, $209-212$.

Regan, D., \& BeVerLey, K. I. (1978b). Looming detectors in the human visual pathway. Vision Research, 18, 415-421.

REgAN, D., \& BeVERLEY, K. I. (1979). Visually guided locomotion: Psychophysical evidence for a neural mechanism sensitive to flow patterns. Science, 205, 311-313.

REGAN, D., \& BEVERLEY, K. I. (1982). How do we avoid confounding the direction we are looking and the direction we are moving? Science, 215, 194-196.

REGAN, D., \& BEVERLEY, K. I. (1985). Visual responses to vorticity and the neural analysis of optic flow. Joumal of the Optical Society of America A, 2, 280-283.

Regan, D., \& Cynader, M. (1979). Neurons in area 18 of cat visual cortex selectively sensitive to changing size: Nonlinear interactions between responses to two edges. Vision Research, 19, 699-711.

Rieger, J. H., \& LAwToN, D. T. (1985). Processing differential image motion. Journal of the Optical Society of America A, 2, 354-360.
Rogers, B., Graham, M. (1979). Motion parallax as an independent cue for depth perception. Perception, 8, 125-134.

Rogers, B., \& Graham, M. (1982). Similarities between motion parallax and stereopsis in human depth perception. Vision Research. 22. 261-270

Rogers, B., \& Graham, M. (1983). Anisotropies in the perception of three-dimensional surfaces. Science, 221, 1409-1411.

Rogers, B., \& Graham, M. (1985). Motion parallax and the perception of three-dimensional surfaces. In D. T. Ingle, M. Jeannerod. \& D. N. Lee (Eds.), Brain mechanisms and spatial vision (pp. 95-111). Dordrecht: Martinus Nijhoff.

Saito, H., Yukie, M., Tanaka, K., Hikosaka, K., Fukada, Y., IWAI, E. (1986). Integration of direction signals of image motion in the superior temporal sulcus of the macaque monkey. Joumal of Neuroscience, 6, 145-157.

SCHIFF, W., \& DETWILER, M. L. (1979). Information used in judging impending collision. Perception, 8, 647-658.

Siegel, R. M., ANDersen, R. A. (1988). Perception of threedimensional structure from motion in monkey and man. Nature, 331 , 259-261.

Simpson, J. I., Graf, W., \& Leonard, C. (1981). The coordinate system of visual climbing fibers to the flocculus. In A. F. Fuchs \& B. Becker (Eds.), Progress in oculomotor research (pp. 116-127). New York: Elsevier.

Simpson, W. A. (1988). Depth discrimination from optic flow. Perception, 17, 497-512.

TANaKa, K., Fukada, Y., \& Sarto, H. (1989). Underlying mechanisms of the response specificity of expansion/contraction and rotation cells in the dorsal part of the medial superior temporal area of the macaque monkey. Journal of Neurophysiology, 62, 642-656.

TANAKA, K., \& SaITO, H. (1989). Analysis of motion of the visual field by direction, expansion/contraction, and rotation cells clustered in the dorsal part of the medial superior temporal area of the macaque. Journal of Neurophysiology, 62, 626-641.

ToDD, J. T. (1981). Visual information about moving objects. Joumal of Experimental Psychology: Human Perception \& Performance, 7 , 795-810.

Tresilian, J. R. (1990). Perceptual information for the timing of interceptive action. Perception, 19, 223-239.

Treue, S., Husain, M., \& ANDersen, R. A. (1991). Human perception of structure from motion. Vision Research, 31, 59-75.

WARREN, W. H., \& HANNON, D. J. (1988). Direction of self-motion is perceived from optical flow. Nature, 336, 162-163.

Warren, W. H., Morris, M. W., Kalish, M. (1988). Perception of translational heading from optical flow. Journal of Experimental Psychology: Human Perception \& Performance, 14, 646-660.

Waxman, A. M., \& WoHn, K. (1988). Image flow theory: A framework for 3-D inference from time-varying imagery. In C. Brown (Ed.), Advances in computer vision (Vol. 1, pp. 165-224). Hillsdale, NJ: Erlbaum.

\section{APPENDIX A}

Figure A1 illustrates the image geometry for an observer moving at constant velocity, $z^{\prime}$, relative to a point, $P$. Following Lee (1976), we define the temporal proximity, $\tau$, of this point as the time until the observer crosses the plane that contains the point and is perpendicular to the direction of movement. Note that the observer may never actually contact $P$, which is another reason why we refer to temporal proximity, rather than timeto-contact. By definition,

$$
r=z l-z^{\prime}
$$

where $-z^{\prime}$ is the velocity of the plane in the direction of the observer. From similar triangles,

$$
r / f=s / z
$$

so that

$$
r z=s f
$$




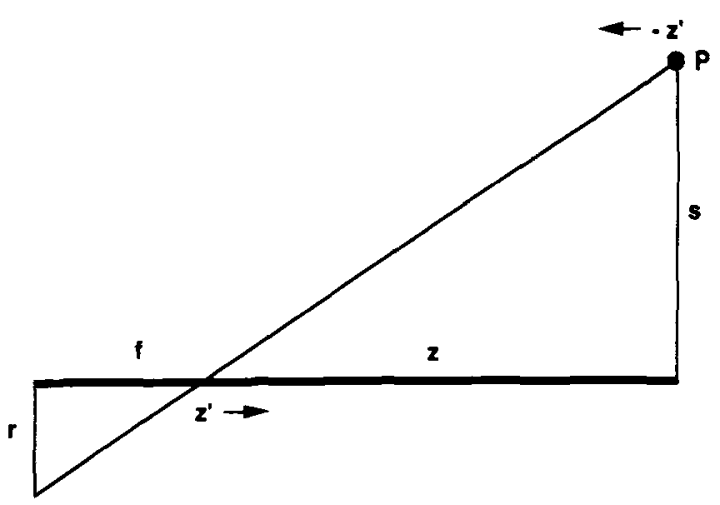

Figure A1. The geometry of temporal proximity.

Differentiating with respect to time gives

$$
r z^{\prime}+r^{\prime} z=0
$$

or

$$
r / r^{\prime}=z /-z^{\prime}=\tau
$$

Thus, temporal proximity can be extracted simply by measuring the velocity of any point in the image, $r^{\prime}$, and its distance from the focus of expansion, $r$.

Differentiating Equation $\mathrm{A} 1$ again with respect to time gives

$$
r z^{\prime \prime}+2 r^{\prime} z^{\prime}+r^{\prime \prime} z=0
$$

or, since movement is at a constant velocity so that $z^{\prime \prime}=0$,

$$
2 r^{\prime} / r^{\prime \prime}=z /-z^{\prime}=\tau
$$

so that temporal proximity can also be extracted by measuring the change in velocity over time at any point in the image.

\section{APPENDLX B}

Information about temporal proximity $(\tau)$ is also present in the changes in overall dot density $(\rho)$.

$$
\rho=\text { number of dots/area }=n / \pi r^{2}
$$

so that

$$
\rho r^{2}=n / \pi \text {. }
$$

Differentiating with respect to time,

$$
\rho^{\prime} r^{2}+2 \rho r r^{\prime}=0
$$

so that

$$
\rho^{\prime}=-2 \rho r^{\prime} / r
$$

and, since

$$
\begin{gathered}
r^{\prime} / r=1 / \tau, \\
\rho^{\prime}=-2 \rho / \tau .
\end{gathered}
$$

Hence,

$$
\tau=-2 \rho / \rho^{\prime} .
$$

(Manuscript received October 21, 1991 ; revision accepted for publication November 15, 1993.) 